\title{
Clinical translational students' perceptions of research ethics coursework: a case study
}

\author{
Linda S. Behar-Horenstein, Huibin Zhang \\ School of Human Development and Organizational Studies in Education, University of Florida, Gainesville, FL, USA
}

\begin{abstract}
Relatively unknown is whether coursework in responsible conduct of research actually achieve the purposes for which it is designed. In this study, the authors report clinical translational students' perceptions of their research ethics coursework and the alignment between course content as recommended in the literature. We used grounded theory to portray emergent findings across focus groups and semistructured interviews among 31 participants at one clinical translational science hub. We also used thematic analysis to analyze course syllabi. Two themes emerged: Averting scientific misconduct and Responding to ethical dilemmas. Students reported that they did not acquire requisite strategies to address research ethical dilemmas. One of the course syllabi indicated the provision of active learning opportunities. However, the findings did not offer support. Developing experiential learning activities and ensuring that course content is aligned with the contemporary ethical practices, such as case study and portfolio development, is recommended.
\end{abstract}

Correspondence: Linda S. Behar-Horenstein, School of Human Development and Organizational Studies in Education, University of Florida, Gainesville, FL, USA.

E-mail: Lsbhoren@ufl.edu

Key words: Responsible conduct of research; Clinical translational science; Student perceptions; Grounded theory; Thematic analysis.

Contributions: LB-H made substantial contributions to the conception or design of the work; the acquisition, analysis, or interpretation of data for the work; drafting the work or revising it critically for important intellectual content; final approval of the version to be published; and agrees to be accountable for all aspects of the work in ensuring that questions related to the accuracy or integrity of any part of the work are appropriately investigated and resolved. $\mathrm{HZ}$ made substantial contributions to the analysis, or interpretation of data for the work; drafting the work or revising it critically for important intellectual content; final approval of the version to be published; and agrees to be accountable for all aspects of the work in ensuring that questions related to the accuracy or integrity of any part of the work are appropriately investigated and resolved.

Conflict of interest: the authors declare no potential conflict of interest.

Funding: research reported in this publication was supported by the National Center for Advancing Translational Sciences of the National Institutes of Health under University of Florida Clinical and Translational Science Awards TL1TR001428, KL2TR001429, and UL1TR001427. The content is solely the responsibility of the authors and does not necessarily represent the official views of the National Institutes of Health.

Received for publication: 17 November 2018.

Revision received: 31 January 2019.

Accepted for publication: 31 January 2019.

This work is licensed under a Creative Commons Attribution NonCommercial 4.0 License (CC BY-NC 4.0).

(C) Copyright L.S. Behar-Horenstein and H. Zhang, 2019

Licensee PAGEPress, Italy

Qualitative Research in Medicine \& Healthcare 2019; 3:15-24

doi:10.4081/qrmh.2019.7943

\section{Introduction}

Training in translational science aims to help participants transfer fundamental research discoveries from laboratory into clinical practice. Decades ago, the National Institute of Health issued funding mechanisms, referred to as Clinical and Translational Science Awards (CTSAs) to support university development of a clinical translational science institutes (CTSI) and a cadre of physician-scientists whose research aims are directed at achieving translational science goals. The processes directed towards helping students develop an understanding and acquiring related practices necessary to conducting translational science are not well documented. ${ }^{1-4}$ Translational science institutes across the US support students through TL1 (predoctoral training) and T32 (pre- and postdoctoral training) funding mechanisms. Educational experiences in these training programs have generally focused on cultivating collaboration with seasoned translational scientists while students also take coursework related to team science, translational science models and research ethics. However, studies on the development of translational science educational environments and on the teaching of research ethics are scarce. ${ }^{5}$ The purpose of this study was to analyze clinical translational science students' perceptions of their research ethics coursework, through interviews ${ }^{6}$ and focused groups. A second purpose was to describe how well the course content and instructional strategies aligned with the principles of ethical training as described in the literature.

\section{Teaching research ethics in translational science}

DuBois et al. ${ }^{7}$ identified what content should comprise coursework in responsible conduct of research. Kon et al. ${ }^{8}$ also provided a summary of current materials used across clinical translational science hubs. Similar to the Office 
of Research Integrity ${ }^{9}$ Kon et al. recommended content domains i) data acquisition, management, sharing, and ownership; ii) mentor/trainee responsibilities; iii) publication practices and responsible authorship; iv) peer review; v) collaborative science; vi) human subjects; vii) research involving animals; viii) research misconduct; and ix) conflict of interest and commitment).

We adopted Helton-Fauth et al. ${ }^{10}$ four dimensions of research ethics: data management, study conduct, professional practices and business practices for this study because it was the most contemporary framework. Data management refers to the appropriate methods for handling and reporting data. Study conduct refers to informed consent and debriefing, confidentiality, and the treatment of human and animal participants according to board guidelines. Professional practices refer to protection of intellectual property, protection of public welfare and the environment, adhering to professional commitments, mentoring, and the treatment of collaborators. Business practices refer to contract and grant bidding, the use of physical resources, conflict of interest, and laboratory management. Gaining insight into how well these dimensions are enacted in research ethics education needs to be examined.

Researchers have shown that approaches to teaching the responsible conduct of research (RCR) tend to negate the importance of developing tolerance and responding appropriately to complex ethical dilemmas. Antes et al. ${ }^{11} \mathrm{ex}-$ amined the impact of RCR instruction on research ethical decision-making with 173 participants. Results showed that the ethicality of decisions made in relationship to data management, study conduct, and professional practices did not improve or decline following instruction. Also, following the completion of the RCR course, the ethicality of participant's business related decisions (i.e., contract bidding) decreased. Individual awareness of situational elements and their ability to weigh personal motivations improved. However, with regard to the social elements of ethical problems, they were more internally focused and closed off when making decisions. Antes et al. ${ }^{11}$ concluded that when instructors exaggerate evading ethical dilemmas, students develop unrealistic expectations about their capabilities to handle ethical problems. These researchers showed that the RCR research ethics courses may not be effective or may even be harmful. ${ }^{7}$ They recommended exploring possible obstacles and characteristics of effective research ethics education in future studies.

Yarborough and Hunter ${ }^{12}$ argued that the role of research ethics is not sufficiently emphasized in science at the graduate and postgraduate levels. They emphasized the Presidential Commission for the Study of Bioethical Issues Moral Science: Protecting Participants in Human Subjects Research ${ }^{13}$ report recommendations, which suggested creating a culture of responsibility, as well as utilizing creative and innovative approaches in teaching research ethics. Moreover, they advised that research ethics instructors focus on teaching researchers how to avoid misconduct and counsel them about what they must and must not do.

\section{Experiential learning theory}

This study is grounded in the well-established Experiential Learning Theory (ELT).${ }^{14}$ This model posits that acquisition of new knowledge and skills depends on a cycle of successive learning experiences. The premise underlying ETL is that learning evolves via four types of engagement: i) experiential (i.e., concrete experience) whereby researchers gather information from the world (e.g., observations of inappropriate author attribution); ii) reflective (i.e., reflective observation) whereby researchers take time to think, process, organize and relate inputs to other known factors that surround that experience (e.g., why PIs falsify data); iii) abstract (i.e., abstract conceptualization) whereby researchers create new meanings and develop new ways of looking at existing information (e.g., how data falsification differs among senior and junior researchers); and iv) action (i.e., active experimentation) whereby researchers actively test a hypothesis (e.g., using an existing dataset, the researcher tests her emergent hypothesis that senior faculty tend to falsify data more frequently than junior faculty). This new knowledge is then re-introduced back into the learning cycle. However, the cycle is in continuous flux as researchers engage in experiences inside and outside the learning environment. The ELT promotes reflective conversation that enables researchers to shape their responses to project goals (e.g., creating a conversational space for members to reflect on their experiences with research ethical dilemmas) while applying and assessing the utility of new knowledge ${ }^{15,16}$ ELT stimulates sharing the functional role of the leadership ${ }^{17}$ whereby personal needs are replaced by shared roles necessary for meeting project or team goals. $\mathrm{Kolb}^{18}$ showed that the training of researchers or teams are cultivated by sharing experiences and reflecting on the meaning of those experiences together.

\section{Materials and Methods}

\section{Participants}

Prior to beginning the study, IRB approval was granted (IRB \#2015-U-0988). The study sample ( $\mathrm{n}=31$ out of 53 or $58 \%$ ) included 5 predoctoral and 10 postdoctoral fellows funded by a T32 award and 16 students funded by a TL1 award. Participants were drawn from all students (15 predoctoral, 17 postdoctoral, and 21 TL1 students) enrolled in one or more of the RCR courses at a single CTSI hub over a two-year period. Postdoctoral fellows were funded by the National Research Service Awards postdoctoral training program (T32), which is designed to ensure that a diverse and highly trained workforce is available to meet the nation's biomedical, behavioral, and clinical research needs. TL1 graduate stu- 
dents funded by a CTSA award were expected to acquire the skills needed to develop a career in multidisciplinary clinical and translational research. Mentoring and didactic training was provided for all participants. Also, while enrolled in the program, participants performed clinical and/or translational research in health-related fields. Per grant requirements, all T32 and TL1 trainees were also required to enroll in one of the two academic health science center's research ethics courses: RCR or the Ethical Policy Issues in Clinical Research.

\section{Procedures}

We conducted 15 semi-structured interviews with T32 pre- and post-doctoral students. Interviews ranged from 17-55 minutes. Five focus groups, ranging from 60-90 minutes, were conducted with 4-6 pre-doctoral TL1s. We conducted interviews with sets of T32 trainees because they worked in different laboratories. This approach was the easiest way to encourage their participation in the study. Since TL1 trainees were cohort groups, we used focus groups to access their perceptions. The purpose of the interview and focus groups protocols was to evaluate the program's effectiveness in providing relevant training experiences. We asked students to describe to what extent they believed that coursework prepared them to avoid misconduct and how to deal with scientific ethical dilemmas. We also asked them to provide specific examples of learning activities that they considered instrumental in increasing their knowledge of RCR and skills. The same questions were used for both data collection types.

\section{Data analysis}

The researchers, a senior professor in education, and a $2^{\text {nd }}$ year doctoral student in school psychology independently analyzed the compiled data by applying a constructivist, grounded-theory approach as described by Charmaz. ${ }^{19}$

Prior to the analysis, we assigned pseudonyms to each participant. Both Behar-Horenstein and Zhang read each of the focus group and interview transcripts line-by-line as a separate entity. Each of us developed a list to denote emergent themes and described each theme in 4-6 words. We met to discuss our independent notions of the emergent themes. Then, we used open coding while reading line by line. We compared open coding to ensure that a systematic approach to analysis was occurring before moving on to develop categories and emergent themes. The authors reached consensus on the identification of the categories as well as on the two themes that emerged in this study, awareness of ethical violations and responding to ethical dilemmas. Consistent with Charmaz's ${ }^{19}$ guidance, we used gerunds to connote observable and conceptual action in the data. Each researcher tagged text and we audited each other's selected text to ensure agreement.
We illustrate the progression from open codes to categories/axial codes and themes in the following examples. For a portion of the focus group text that read: $I$ think that's more of the benefits of the course, it just gives you the vocabulary to say this is how I identify this is wrong, this is the kind of... it was open coded as developing vocabulary. Next, it was conceptualized as belonging to the category/axial code ethical violation belonging to the theme, Awareness of ethical violations. How interview data was coded can be seen in the following example. The text that read: Depends on the $d y$ namics of the relationship with whoever is scientific misconduct is occurring with, and there is no clear-cut answer was open coded as Responding depends on $d y$ namics. This text was conceptualized as belonging to the category/axial code, Ethical dilemma response, belonging to the theme, Responding to ethical dilemmas. There were two axial codes, Ethical violation corresponding to theme, Awareness of ethical violations, and Ethical dilemma response corresponding to theme, Responding to ethical dilemmas. An audit trail shows progression from selected interview and focus group data to open coding, categorization, themes, and their related conceptual definitions (Table 1).

The use of two independent coders aided us in reducing the potential for bias. Reading line-by-line and coding segments assisted in making supporting quotations more accessible. Data were analyzed by coding and identifying participants' spoken words to support the categories that were identified. This rigorous and systematic approach allowed us to feel confident that what we report is representative of participants' perspectives.

Attention to credibility, and confirmability facilitated establishing trustworthiness. Credibility, confidence in the truth of the findings, was achieved through triangulation and peer debriefing. Triangulation was accomplished by: i) using two analysts; ii) reviewing multiple interview transcripts; iii) using qualitative line by line coding and peer debriefing to ensure the accuracy of interpretations. Confirmability was achieved by engaging more than one person in analyzing the data.

\section{Analysis of course syllabi}

We used thematic analysis ${ }^{20}$ to analyze the two ethics course syllabi. First, we applied Helton-Fauth's et al. ${ }^{10}$ four dimensions of research ethics to search for what we could argue was evidence of content, aligned with topics in data management, study conduct, professional practices, and business practices. Next, we reviewed the syllabi for the presence or absence of described learning experiences and examined the syllabi for a description of instructional methods used (e.g., lecture, small group discussions) and evidence of experiential learning activities (e.g., student led-discussions or presentations, exploration of research ethics case studies). 


\section{Results}

\section{Awareness of ethical violations}

This theme was defined conceptually as, having a clear idea of how to recognize what constitutes unethical conduct (e.g., falsifying data, inappropriately handling, storing sharing, and reporting data, not treating human and animal subjects according to board guidelines, accepting authorship without meeting acceptable guidelines for intellectual contributions). Representative examples showed that participants described if and how research ethics coursework offered adequate preparation to help them avoid unethical misconduct. Their views on whether the research ethics coursework would help them avert scientific misconduct and if they received adequate preparation to avoid misconduct were mixed. Five (16\%) participants believed that they already knew how to prevent scientific misconduct from past experiences or from interaction with mentors. Coursework did not change their perspective on ethical misconduct. Beverly shared that, I don't think T32 specifically will help me to avert scientific misconduct. I think that's just something you learn from your mentors. Diane said, That's one where I see a little bit less impact on what
I've been doing just because I used to work as the project manager. All of my background is very focused on ethics training. Similarly, John asserted that, My academic program and my department already have a lot of emphasis on research conduct, and so I don't think that the T32 has really added to that. Both Diane and John asserted that they obtained requisite knowledge on averting unethical actions prior to entering the program.

$10(32 \%)$ participants believed that the course would help them avert scientific misconduct. Several participants noted feeling confident about this specific issue. Andrew said, I think being forced [to] interact with people who are medically oriented... pushes me further away from scientific misconduct... Susan felt that learning about the importance of interpreting data in a less biased fashion in the research ethics course would assist her in averting scientific misconduct in the future. The responses suggested the courses helped some trainees recognize science misconduct more easily and would likely ensure that they avoided it in future interactions.

Ten $(32 \%)$ participants opined that the research ethics course would not help them avert scientific misconduct. For example, Robbie reported having no ethical training within the program. Natasha did not believe the ethical

Table 1. Audit trail progression: selected interview (I) or focus group (FG) data, open coding, categories/axial codes, themes, and conceptual definitions.

\begin{tabular}{|c|c|c|c|c|}
\hline I and FG data & Open codes & Categories/Axial codes & Themes & Conceptual definition \\
\hline $\begin{array}{l}\text { I think that's more of the } \\
\text { benefits of the course, it just } \\
\text { gives you the vocabulary to } \\
\text { say this is how I identify } \\
\text { this is wrong, this is the } \\
\text { kind of... (FG) } \\
\text { For me, it just creates } \\
\text { awareness for us being } \\
\text { in the scientific community } \\
\text { because actually, I didn't } \\
\text { realize, learning through } \\
\text { all these examples I've } \\
\text { learned in class so far, } \\
\text { how common it is. (FG) }\end{array}$ & Developing awareness & Ethical violation & $\begin{array}{l}\text { Awareness of ethical } \\
\text { violations }\end{array}$ & $\begin{array}{l}\text { Having a clear idea of how } \\
\text { to recognize what } \\
\text { constitutes unethical } \\
\text { conduct (e.g., falsifying } \\
\text { data, inappropriately } \\
\text { handling, storing } \\
\text { sharing, and reporting } \\
\text { data, not treating human } \\
\text { and animal subjects } \\
\text { according to board } \\
\text { guidelines, accepting } \\
\text { authorship without } \\
\text { meeting acceptable } \\
\text { guidelines for intellectual } \\
\text { contributions) }\end{array}$ \\
\hline $\begin{array}{l}\text { Depends on the dynamics } \\
\text { of the relationship with } \\
\text { whoever is scientific } \\
\text { misconduct is occurring } \\
\text { with, and there is no } \\
\text { clear-cut answer. (I) } \\
\text { It would depend on what } \\
\text { they were doing if that's } \\
\text { something that could be } \\
\text { addressed directly with } \\
\text { them... maybe just something } \\
\text { that they overlooked and } \\
\text { didn't realize they were } \\
\text { doing vs something that } \\
\text { was deliberately depends. (I) }\end{array}$ & $\begin{array}{l}\text { Responding depends } \\
\text { on dynamics }\end{array}$ & Ethical dilemma response & $\begin{array}{l}\text { Responding to ethical } \\
\text { dilemmas }\end{array}$ & $\begin{array}{l}\text { Acquiring strategies or } \\
\text { principles to effectively } \\
\text { address situations, in } \\
\text { which scientific } \\
\text { misconduct occurs, } \\
\text { especially with people } \\
\text { who they had have } \\
\text { special relationships } \\
\text { with you, such as } \\
\text { mentors or peers }\end{array}$ \\
\hline
\end{tabular}


class helped her to avert scientific misconduct. Cindy reasoned that, if you are going to be an ethical person, you are going to be an ethical person. She asserted that taking a research ethics class was inconsequential. Julie shared that she did not, ...think that the CTSI has a huge emphasis on that scientific misconduct. Maybe just because I just took an ethics class like a little while ago you know... Proportionally, the number of participants who did and did not believe that research ethic courses changed their perception of science misconduct was the same. This finding suggested that perhaps the courses were not instrumental in augmenting participant knowledge of research ethics or in promoting their understanding of how to avert and address it. The remaining six (19\%) participants did not share opinions regarding whether the course was helpful in their prospective efforts to avert scientific misconduct.

Among those 10 (32\%) participants who believed that the course would help them avert scientific misconduct, five $(16 \%)$ participants reported that the coursework provided them with a clear idea of how to recognize what constitutes unethical conduct (e.g., managing data, inappropriately, not treating human and animal subjects according to board guidelines, accepting authorship without meeting acceptable guidelines for intellectual contributions). Eight (26\%) participants talked about their awareness of ethical violations and remarked that the research ethic courses had improved their awareness. For example, Sue reported that, It's easy to not realize that it might not be ethical, but at least it points it out and makes it - now to me I think it's more obvious, now that I've been exposed to it and I can tell.

Six $(19 \%)$ participants shared that their awareness of ethical violations had improved by talking about unethical examples. Violetta acknowledged that ... you cannot change the trend of the data because then you would be falsifying the data. Daniel felt that one benefit of the course was acquiring the vocabulary to say this is how I identify [that] this is wrong. Sue pointed out how class content and interactions helped her appreciate that, It's easy to not realize that it might not be ethical, but at least it points it out and makes it...more obvious, now that I've been exposed to it. Evie pointed out that coursework examples made her realize just how common it is. Learning about potential ethical violations raised participant cognizance of what constitutes misconduct and helped them recognize that it was more prevalent than they thought.

\section{Responding to ethical dilemmas}

This theme was defined conceptually as, acquiring strategies or principles to effectively address situations, in which scientific misconduct occurs, especially with people who they had have special relationships with you, such as mentors or peers. Exemplification of this theme was evidenced by participants describing if their coursework offered strategies to help them address scientific misconduct.
Sue said:

In that course they talk about how if you experience it, how to approach the correct people, like the Research Integrity Office, to think of your specific university, if it were to get to that point, but also how to try to recognize the problem if you see it in your lab setting [such as] how it can affect your research [or] how to talk to your PI maybe and/or if you think that that's what's happening. I haven't been exposed to that thankfully, but I feel like if it were to happen, [now I have a better sense of] what actions to take.

Anthony said the course content and interactions, raise [d] awareness of how things aren't black and white, but the principals involved in it, staying briefed on it and honestly reinforcing that the end never justify the means with any research endeavor... Only one person talked about particular instructional strategies used in the courses such as role play or the types of learning activities (i.e., developing their own research ethics case and potential responses, debating ethical responses to cases involving transplantation, genetic testing, or cloning). Cindy reported that participants never really learned exactly how to confront someone committing ethical misconduct because it mainly focused on cases that had happened in the past. Thus, students received little to no strategies or approaches for how to respond to observations of unethical behavior. They did not report who to go to if they saw a problem. This finding points to a need teaching participants about potential on the approaches that could be used while responding to unethical behaviors. When talking about how to respond to ethical dilemmas, three (10\%) participants believed that they had received clear directions or guidance.

Participants acknowledged that that their response to a violation would depend on the interactional context and on the type of ethical issues they observed. Cory stated that his reaction to an ethical dilemma would depend on the dynamics of the relationship with whoever the scientific misconduct is occurring with, and there is no clearcut answer. His comment points out the imminent, but multi-faceted conflict that ensues when misconduct is caused by individuals who mentor and fund student research. Jordan said that his course helped him realize that things are not black and white, and acknowledged that there were ethical principles he could use as references. Larry appreciated learning about the ambiguity of ethical dilemmas. He claimed that grey areas are mine every day and now understood that individuals could make, just bad decisions or careless ones. Summary sentence here.

Three (10\%) participants felt confident that they could handle challenges related to ethical misconduct because they learned related strategies from previous classes, or they believed they could find people with whom they could seek their counsel. Notably, these participants ref- 
erenced courses that were not included in this study. Kate who had taking another research ethics class that was not part of this study, reported that she acquired a solutionfocused perspective, an ability to recognize problems, and would seek help from others.

Only three $(10 \%)$ participants said that when faced with an ethical dilemma they would contemplate its nature before taking any action. This response signifies their uncertainty. In contrast, Diane reported that if faced with unethical mentor behavior that initially she would try to determine the feasibility of discussing the situation directly with person directly involved and assess if it was a conscious action or an overlooked mistake.

Only three $(10 \%)$ participants reported that they obtained new insight about how to handle ethical dilemmas although they did not offer more specific details. Suzi said, It's been helpful and then it also brings up a lot of dilemmas that I didn't really know still existed when considering placebo-controlled trials. While claiming that she acquired insight into how to resolve dilemmas, she did not describe specific strategies that would guide her reactions.

\section{Analysis of ethics courses}

Using thematic analysis ${ }^{20}$ of the RCR course syllabus, we found that while it covered Helton-Fauth's et al..$^{10}$ four dimensions of research ethics. However, only one element within the business practices - conflict of interest - was referenced in the syllabi. The findings showed that course content did not include consent and debriefing, confidentiality, mentoring, protection of public welfare and environment, contract and grant bidding, the use of physical resources, and laboratory management.

The Ethical Policy Issues in Clinical Research course covered four dimensions of research ethics. However, it did not include coverage of mentoring, treatment of collaborators, contract and grant bidding, the use of physical resources, and laboratory management (Table 2).

Neither of the research ethics course syllabi included a list of course goals and course objectives or a description of instructional delivery methods, assignments, or evaluation methods. Although the RCR course listed a numerical scale for assigning letter grades (unlike the Ethical Policy Issues in Clinical Research course), the linkage between student work and how assignments were graded was not described. From a pedagogical perspective, these syllabi would leave most students asking what tangible learning outcomes they would be able to demonstrate by the conclusion of these courses. Without a list of learning objectives, it is difficult to appreciate where the instructor is headed and what students are expected to be able to do. ${ }^{21} \mathrm{~A}$ lack of clarity regarding course objectives and student work products likely influenced the apparent lack of experiential teaching and ultimately the quality of student experiences. ${ }^{21}$ Other than the mention of team-based learning for some RCR course sessions, there was no de- scription of how learning activities fostered student dialogue or hypothetical actions to promote effective responses to real world ethical challenges. ${ }^{22,23}$ Also, we found no other information in the RCR course syllabi to demonstrate that active instruction was occurring. In the Ethical Policy Issues in Clinical Research syllabus, the inclusion of interactive analysis of human subject scandals using data and video, discussion of informed consent procedures applied to cases, review of recruiting ads, and critique of informed consent suggested the use of active learning experiences. However, a failure to describe related student work products and processes, calls into question whether such activities were actually provided.

\section{Discussion}

From a theoretical perspective the study findings show that students found the ethics courses to be lacking an emphasis in promoting three of the four types of learning, reflection, abstraction, and action. Students reported little to no opportunity create new meanings, to develop new ways of looking at information, or to actively test hypotheses. ${ }^{14}$ Despite the mentioning of active learning experiences documented in the Ethical Policy Issues in Clinical Research syllabus, students' perceptions did not align. However, consistent with the first ELT level, experiential, students described receiving conceptual information from both courses.

The findings showed that the research ethics courses were effective in raising participant awareness of predominant forms of ethical violations such as, inappropriate data management, failure to treat human or animal subjects appropriately, and violating others' intellectual property. About a third of the participants believed that the courses would help them avert prospective unethical misconduct while another third disagreed. The remainder expressed no opinion one way or another or stated that they already knew how to prevent scientific misconduct. Many participants found the research ethics courses peripheral to their interests, or even a distraction from what they consider their real work.

None of the participants reported acquiring specific strategies regarding how, if presented with an ethical dilemma in the future, they would address those dilemmas. Overall, participants were not being well enough equipped to address ethical dilemmas. This raises questions regarding the potential impact for them going forward as professional/academic researchers and, in turn, on their students, and with those with whom projects are conducted. These findings suggest that greater effort must be devoted to identifying specific guidelines to help students handle dilemmas. ${ }^{24}$ Several participants reported that they had no idea how they would actually respond if presented with an ethical dilemma. Consistent with Domen's ${ }^{25}$ suggestion, research ethics educational experiences ought to focus not only on conveying relevant knowledge but also on foster- 
ing ethical problem-solving skills.

Bærø $\mathrm{e}^{22}$ proposed adopting a medical framework to use when making ethical decision. He recommended a five-step process that includes: i) identification of the ethical challenge; ii) development of a normatively justified approach; iii) testing of the feasibility of the proposed approach in a real-world setting; iv) implementation of the adjusted result; and v) evaluation of the resulting practice. Unsurprisingly, none of the participants talked about how to make ethical decisions based on this model.

Table 2. Thematic analysis of ethics topic coverage and learning activities in the responsible conduct of biomedical research and ethical policy issues in clinical research courses.

\begin{tabular}{|c|c|c|c|c|}
\hline & $\begin{array}{l}\text { Responsible conduct } \\
\text { of biomedical research }\end{array}$ & $\begin{array}{l}\text { Evidence of learning } \\
\text { activities }\end{array}$ & $\begin{array}{l}\text { Ethical policy issues } \\
\text { in clinical research }\end{array}$ & $\begin{array}{l}\text { Evidence of learning } \\
\text { activities }\end{array}$ \\
\hline \multicolumn{5}{|l|}{$\begin{array}{l}\text { Topics* } \\
\text { Data management }\end{array}$} \\
\hline $\begin{array}{l}\text { Appropriate methods of } \\
\text { handling, and reporting data }\end{array}$ & $\begin{array}{l}\text { Yes/Data Management } \\
\text { Practices }\end{array}$ & None & $\begin{array}{l}\text { Yes/Issues in genetics } \\
\text { and human embryonic } \\
\text { stem cells, Fraud, } \\
\text { fabrication and falsification } \\
\text { of data }\end{array}$ & Regulation cases \\
\hline Study conduct & Yes & & Yes & \\
\hline Consent \& debriefing & No & None & $\begin{array}{l}\text { Yes/Informed Consent } \\
\text { in Research }\end{array}$ & $\begin{array}{l}\text { Critique of informed } \\
\text { consents Translation of } \\
\text { protocol language } \\
\text { comprehensible to lay } \\
\text { audience }\end{array}$ \\
\hline Confidentiality & No & None & $\begin{array}{l}\text { Yes/Maintaining the } \\
\text { Confidentiality of } \\
\text { Research Data }\end{array}$ & Case studies \\
\hline $\begin{array}{l}\text { Treating human participants } \\
\text { according to board guidelines }\end{array}$ & $\begin{array}{l}\text { Yes/Protection of Human } \\
\text { Subjects }\end{array}$ & None & $\begin{array}{l}\text { Yes/Clinical Research with } \\
\text { Special Populations: } \\
\text { Children and Adolescents/ } \\
\text { Clinical Research with } \\
\text { Special Populations: } \\
\text { Cognitively Impaired People, } \\
\text { Prisoners, Soldiers and } \\
\text { Students }\end{array}$ & $\begin{array}{l}\text { Case studies, } \\
\text { Critiques of recruiting } \\
\text { ads, critique cases } \\
\text { with minors, vulnerable } \\
\text { populations and prisoners }\end{array}$ \\
\hline $\begin{array}{l}\text { Treating animal } \\
\text { participants according } \\
\text { to board guidelines }\end{array}$ & $\begin{array}{l}\text { Yes/Welfare of } \\
\text { Laboratory Animals }\end{array}$ & None & $\begin{array}{l}\text { Yes/Ethical Use of Animals } \\
\text { in Research }\end{array}$ & None \\
\hline Professional practices & Yes & & Yes & \\
\hline $\begin{array}{l}\text { Protection of intellectual } \\
\text { property }\end{array}$ & $\begin{array}{l}\text { Yes/Authorship \& } \\
\text { Publication }\end{array}$ & None & $\begin{array}{l}\text { Yes/Ethical issues in light } \\
\text { of intellectual property } \\
\text { issues/Rules of Authorship }\end{array}$ & $\begin{array}{l}\text { Outline criteria for } \\
\text { determination of authorship. } \\
\text { Application of misconduct } \\
\text { procedures }\end{array}$ \\
\hline $\begin{array}{l}\text { Protection of public welfare } \\
\text { and environment }\end{array}$ & No & None & $\begin{array}{l}\text { Yes/Ethical issues in } \\
\text { community engagement } \\
\text { research }\end{array}$ & Case studies \\
\hline $\begin{array}{l}\text { Adhering to professional } \\
\text { commitments }\end{array}$ & $\begin{array}{l}\text { Yes/Avoiding Research } \\
\text { Misconduct }\end{array}$ & None & Yes & $\begin{array}{l}\text { Explain the procedures for } \\
\text { reporting and investigating } \\
\text { misconduct in research }\end{array}$ \\
\hline Mentoring & $\begin{array}{l}\text { Yes/Mentor \& Trainee } \\
\text { Responsibilities }\end{array}$ & None & No & None \\
\hline Treatment of collaborators & Yes/Collaborative Research & None & No & None \\
\hline Business practices & Yes & & Yes & \\
\hline Contract and grant bidding & No & None & No & None \\
\hline Use of physical resources & No & None & No & None \\
\hline Conflict of interest & $\begin{array}{l}\text { Yes/Conflicts of Interest } \\
\& \text { Commitment }\end{array}$ & None & Yes/Conflicts of Interest & Critique of cases \\
\hline Laboratory management & No & None & No & None \\
\hline
\end{tabular}

*Denotes yes to indicate if topic was described in syllabus or no if it was not taught, and if appropriate indicates what content domain. 
Also absent from student discussion was an explicit conversation as recommended by Bærøe regarding how to counteract identified barriers to ideal decision-making, regarding the context (e.g., resource scarcity, geographic and demographic challenges), biased distribution of opportunities among individuals (e.g., voicing concern, deliberating a processing information, reaching a conclusion and acting on it), and pragmatic barriers that undermine feasibility (e.g., the organization of information flow in institutions). ${ }^{22}$ Students made only a passing reference to the interplay between the importance of gaining theoretical and practical ethical knowledge when they hypothesized how they might respond to misconduct committed by a mentor. Otherwise, participants did not describe challenges related to the real world of practice and ethical decision-making ${ }^{22}$ Moreover, none of the participants discussed how organizational systems or cultural norms might ultimately contribute to impeding human research subject protection. ${ }^{26}$

None of the participants discussed the inherent challenges related to providing informed consent when it embraced clinical situations new to both patient and clinician, or how the informed consent process might be impacted by issues involving transplantation, genetic testing, or cloning. ${ }^{27}$ Also, no participant referenced how they might respond to ethical and scientific issues related to the use of health technologies, the ethics of randomization, clinical trials $^{28}$ or non-medical tasks, such as information technology, engineering, nanotechnology, and economy. ${ }^{23}$

Although Hostiuc et al..$^{23}$ argued that the practice of research ethics should be concordant with the elements of the translational process: phases, gaps, and data transfer, not a single participant referred to these matters. Along the same lines there was no evidence showing that participants discussed critical ethical questions coming from interactions between investigators, IRBs and regulators. Along the same lines, participants did not describe the kind of attention they should demonstrate towards trial safety dimensions such as disease gene transfer trial. ${ }^{29}$

Analysis of the courses showed that both covered most of the recommended content domains of research ethics. However, there was little evidence to illustrate the use of learning activities in the RCR course that could have otherwise promoted deep student understanding of the practical application of research ethics information. Although some of active learning experiences were listed in the Ethical Policy Issues in Clinical Research syllabus, without description of related student work products or other outcomes, we cannot discern if such activities took place. These findings suggest that neither course may not have been adequately equipping students to address ethical dilemmas in the profession. From our analysis, it seems likely that both instructors relied heavily on a passive teaching approach characterized by dissemination of information.

Antes et ll. $^{7}$ used scenarios to measure ethical deci- sion-making. However, as shown in this study neither course employed role play or scenarios that might foster practice and application of what students were taught in class. With respect to topics pertaining to: i) treating human participants according to board guidelines, ii) protection of intellectual property, iii) adhering to professional commitments and iv) coverage of conflicts of interest, there was no information regarding whether this was an individual or group activity. Additionally, the assessment of student work products was not described.

Kon et al. ${ }^{8}$ and Dubois et al. ${ }^{7}$ focused on RCR course content and materials. They recommended assessing the effectiveness of courses to determine whether existing RCR training programs are effective in achieving their intended purposes, while noting that it is a limitation of most studies. ${ }^{30-32}$ Although this study represents a single clinical translational hub, it represents a sizeable number of participants.

We suggest that scholars consider methodological changes in future studies. First, we advise researchers to interview course directors, make direct observation of teaching or administer surveys to measure participant ethical knowledge before and after course completion. Second, we suggest differentiating the participants, by their field of study and their level of training, and ethics courses participation to determine if there are subgroup differences. Third, recommend asking participants for their suggestions and recommendations regarding how courses can be improved.

\section{Educational implications and best practices}

In this study, the researchers examined students' perceptions of how well research ethics coursework prepared them to respond to ethical research dilemmas in the clinical translational research workplace. We examined the fit of course content with best practices as described in the literature. As shown, outcomes were not uniformly positive. Limitations associated with course content and instructional practices were also described. We draw upon Klimmelman ${ }^{29}$ and Domen ${ }^{25}$ and ELT to offer recommendations regarding how to improve course effectiveness and achieve desired student outcomes. First, while teaching research ethics, we propose that instructors distribute attention equally between the known and unknown risks of the translational research for all actors who participate in it. ${ }^{7}$ This can be addressed in part by utilizing currently available resources, updating, and revising the course content. Second, we advise adding case-based scenarios that cause students to hypothesize and discuss how they would respond to real world dilemmas in research ethics practice such as: i) counteracting identified barriers; ii) embracing clinical situations new to both patient and clinician; iii) pondering the advances of science and ethical limitations related to transplantation and health technologies; iv) weighing the ethics of randomization, clinical trials, and non-medical tasks, such as information technology, engi- 
neering, nanotechnology, and economy; and v) responding to the phases, gaps, and data transfer inherent to translational research. ${ }^{22}$ Implementing this approach along with experiential learning activities would strengthen student capacity to discuss, demonstrate and write about their reasoning. ${ }^{22-24}$ and bolster their capacity to judiciously weigh competing viewpoints. ${ }^{25}$

Third, we suggest using case-based scenarios and asking students to respond in writing how they would address particular ethical research problems. ${ }^{33-35}$ Further, we suggest asking students to provide evidence that supports their perspective. This activity would move students beyond the stages of concrete experience, reflective observation and abstract conceptualization towards active experimentation and hypothesis testing. Along the same lines, classmates could serve as peer evaluators and provide feedback. ${ }^{34}$ Such an approach would encourage students to introspect, document and provide evidence to support their reasoning while bolstering their skills in written communication. Additionally, it would provide a record of changes for both instructor and student consideration as students gain maturity in their ethical reasoning skills.

Fourth, we endorse fostering student capacity to weigh complex interactional information. We suggest requiring students to develop their own case studies around research ethical dilemmas and include a set of questions for readers to use as they contemplate responding. ${ }^{36}$ This activity would provide additional opportunities to work through and solve research ethical dilemmas as a team.

Also, we commend the use of real-time role play activities during class whereby students would respond in real time to ethical research dilemmas is suggested. Following each role play, the instructor could review student actor responses, engage the class audience in debriefing and ask the students to offer recommendations for alternative responses. ${ }^{33-34}$ This activity would encourage thinking in action and practice in providing prompt responses.

To further strengthen student ability to judiciously weigh interactional information in the face of ambiguity, we suggest assigning a group project that requires students to find a real case and describe how the researchers responded. Similar to the suggestions above, this type of activity would promote the application of newly learned information and provide opportunities for students to speculate about its utility. Consistent with the premise of ELT, ${ }^{14-}$ ${ }^{18}$ each of the aforementioned activities successively builds upon initial knowledge acquisition and moves towards active experimentation. Teaching in this manner is likely to ensure that students develop facility in responding independently and effectively to research ethical dilemmas.

The National Institute of Health requires that all federally funded institutions offer RCR. However, requiring enrollment in research ethics courses is insufficient without a concomitant emphasis on evaluating instruction and student outcomes, suggesting that they are in effect a stamp of approval. To ensure that research ethics courses adequately prepare researchers to handle the complexities of ethical dilemmas in translational science research, we offer several ideas to further this research agenda. First, we recommend evaluating course activities to demonstrate how well teaching research ethics impacts student knowledge, attitudes and skills.

Second, we encourage researchers to simultaneously interview course directors as well as students who completed the courses and compare datasets. Third, we recommend using teaching observations to document the nature of student-faculty interactions. Analysis of this dataset could shed light on how instructional practices impact potential changes in student knowledge, attitudes, and skills. Fourth, we suggest acquiring bigger sample sizes across the nation's CTSIs to amass a large database of student outcomes and insight about the similarities and differences in course content and learning activities. Using a standardized approach to evaluation, comparative findings from such studies might advance the common metrics movement by permitting institutional and intrainstitutional perspectives that showcase outcomes from research ethics coursework. ${ }^{37}$ Fifth, to ensure the contemporariness of educational delivery, we recommend moving these courses to an online format while examining the effect of online teaching and learning outcomes. ${ }^{38}$ Finally, we urge undertaking an analysis of student portfolio documentation of ethical issues and their responses over successive years is recommended to illuminate the manner in which students make meaning and apply their emergent knowledge of research ethics education.

\section{Conclusions}

Using grounded theory and thematic analysis, the authors report clinical translational students' perceptions of their research ethics coursework and the alignment between course content and what is recommended in the literature. While course content focused on most of the recommended dimensions of research ethics, students had little opportunity to actively apply what they were learning and received few strategies to assist them in addressing research ethical dilemmas. We suggest course revisions, supported by experiential learning activities, that aim to ensure that student acquire and utilize requisite tools to address ethical dilemmas in clinical translational research.

\section{References}

1. Allen D, Ripley E, Coe A, Clore J. Reorganizing the general clinical research center to improve the clinical and translational research enterprise. Eval Health Professions 2013;36:492-504.

2. Clinical and Translational Science Awards. Available from: https://ncats.nih.gov/ctsa. Accessed: January 24, 2019.

3. Institute of Medicine. The CTSA Program at NIH: opportunities for advancing clinical and translational research. 
Washington, DC: The National Academies Press; 2013.

4. Pincus HA, Abedin Z, Blank AE, Mazmanian PE. Evaluation and the NIH Clinical and Translational Science Awards: a "top ten" list. Eval Health Professions 2013;36:411-31.

5. Estape E, de Laurido LES, Shaheen M, et al. A multi-institutional, multidisciplinary model for developing and teaching translational research in health disparities. Clin Trans Sci 2011;4:434-8.

6. Loue $\mathrm{S}$. The impact of a research ethics training program. JERHRE 2014;9:46-55.

7. DuBios JM, Schilling DA, Heitman E, et al. Instruction in the responsible conduct of research: an inventory of programs and materials. Clin Transl Sci 2010;3:109-11.

8. Kon AA, Schilling DA, Heitman E, et al. Content analysis of major textbooks and online resources used in responsible conduct of research instruction. AJOB Pri Res 2011;2:42-6.

9. Steneck NH. ORI Introduction to the responsible conduct of research. Washington, DC: U.S. Government Printing Office; 2004.

10. Helton-Fauth W, Gaddis B, Scott G, et al. A new approach to assessing ethical conduct in scientific work. Acct Res: Pol \& Qual Assr 2003;10:205-28.

11. Antes AL, Wang X, Mumford MD, et al. Evaluating the effects that existing instruction on responsible conduct of research has on ethical decision making. Acad Med 2010;85:519-26.

12. Yarborough M, Hunter L. Teaching research ethics better: focus on excellent science, not bad scientists. Clin Trans Sci 2013;6:201-3.

13. Presidential Commission for the Study of Bioethical Issues. Moral science: protecting participants in human subjects research. Available from: https://bioethicsarchive.georgetown.edu/pcsbi/node/558.html Accessed: August 6, 2018.

14. Kolb AY, Kolb DA. Learning styles and learning spaces: Enhancing experiential learning in higher education. Acad Man Learn Educ 2005;4:193-212.

15. Baker AC, Jensen PJ, Kolb DA. Conversational learning: An experiential approach to knowledge creation. Westport, Connecticut: Greenwood Publishing Group; 2002.

16. Dewey J. My pedagogic creed. Curriculum Studies Reader E2. Washington: Routledge; 2013. pp 29-35.

17. Mills M. The sociology of small groups. Upper Saddle River, NJ: Prentice Hall; 1984.

18. Kolb DA. Experiential learning: Experience as the source of learning and development. New Jersey: FT Press; 2014.

19. Charmaz K. Constructing grounded theory: a practical guide through qualitative analysis. London, Thousand Oaks, Calif: Sage Publications; 2006.

20. Aguinaldo JP. Qualitative analysis in gay men's health research: comparing thematic, critical discourse, and conversation analysis. J Homosexual 2012;59:765-87.
21. Nemec PB, Bussema E. Learning objectives. Psychiatr Rehabil J 2010;33:328-30.

22. Bærøe K. Translational ethics: an analytical framework of translational movements between theory and practice and a sketch of a comprehensive approach. BMC Med Ethics 2014;15

23. Hostiuc S, Moldoveanu A, Dascălu M-I, et al. Translational research - the need of a new bioethics approach. J Trans Med 2016;14:16.

24. Colnerud G. Brief Report: ethical problems in research practice. JERHRE 2013;8:37-41.

25. Domen RE. The ethics of ambiguity. Academic Path 2016;3.

26. Strosberg MA, Genefas E, Famenka A. Research ethics review: identifying public policy and program gaps. JERHRE 2014;9:3-11.

27. Kagarise MJ, Sheldon MD. Translational ethics: A perspective for new millennium. JAMA Surg 2000;135:39-45.

28. STREAM research. Available from: http://www.translationalethics.com/ Accessed: August 6, 2018.

29. KIimmelman J. Ethics, ambiguity aversion, and the review of complex translational clinical trials. Bioethics 2011;26:242-50.

30. Kligyte V, Marcy RT, Sevier ST, et al. A qualitative approach to responsible conduct of research (RCR) trining development: identification of metacognitive strategies. Sci Eng Ethics 2008;14:3-31.

31. Anderson MS, Horn AS, Risbey KR, et al. What do mentoring and training in the responsible conduct of research have to do with scientists' misbehavior? Findings from a national survey of NIH-funded scientists. Acad Med 2007;82:853-60.

32. Heitman E, Olson CH, Anestidou L, Bulger RE. New graduate students' baseline knowledge of the responsible conduct of research. Acad Med 2007;82:838-45.

33. Behar-Horenstein LS, Feng X, Isaac C, Lee B. Dental students' expression of cultural competence. J Ethnograph Qual Res 2017;11:171-87.

34. Behar-Horenstein LS, Feng X. Enhancing cultural competence among dental students through active teaching and experiential learning. Qual Rep 2017;22:1169-85.

35. Behar-Horenstein LS, Catalanotto FA, Garvan CW, HudsonVassell CN. An assessment of faculty and dental student decision-making in ethics. J Am Coll Dent 2014;81:44-50.

36. Johnson J, Bagdasarov Z, Connelly S, et al. Case-based ethics education: the impact of cause complexity and outcome favorability on ethicality. JERHRE 2012;7:63-77.

37. Rubio DG. Common metrics to assess the efficiency of clinical research. Eval Health Prof 2013;36:432-46.

38. Silverman H. Strosberg M, Luna F, et al. An analysis of online courses in research ethics in the Fogarty-sponsored bioethics training programs. JERHRE 2013;8:59-74. 